\title{
Trends in Cognitive Function Pre- and Post- Stroke among Chinese Population
}

1 Jianian Hua ${ }^{1,2 \# *}$, Jianye Dong ${ }^{2 \#}$, Yueping Shen $\mathbf{P h D}^{3, * *}$

$2{ }^{1}$ Department of Neurology, The First Affiliated Hospital of Soochow University, Suzhou, Jiangsu, 3 PR China.

$4 \quad{ }^{2}$ Medical College of Soochow University, Suzhou 215123, PR China.

$5{ }^{3}$ Department of Epidemiology and Biostatistics, School of Public Health, Medical College of

6 Soochow University, 199 Renai Road, Suzhou, 215123, PR China.

$7 \quad$ \#These authors contributed equally.

8 *Correspondence:

9 Jianian Hua

10 jnjnhua@foxmail.com

11 **Correspondence:

12 Yueping Shen

13 shenyueping@suda.edu.cn

\section{Abstract}

16 Introduction: To learn the trajectories of cognitive function before and after stroke among Chinese 17 participants.

18 Method: During the seven-year follow-up, 401 participants survived incident stroke and 7551

19 remained stroke free. Cognitive function was assessed by a global cognition score, which included episodic memory, visuospatial abilities, and executive function. A linear mixed model was developed to explore the repeated measurements.

Result: There was no significant difference between the rate of pre-stroke cognitive decline and the decline rate of cognition among stroke-free participants. Among the stroke survivors, the acute decline was -0.123 and $-0.187 \mathrm{SD} / \mathrm{y}$ in cognitive domains of episodic memory and visuospatial ability, respectively. Executive function did not decline acutely after stroke. In the years after stroke, the decline rate of global cognition was $0.074 \mathrm{SD} / \mathrm{y}$ faster than the rate before stroke. The additional decline rate of episodic memory and executive function was 0.043 and $0.061 \mathrm{SD} / \mathrm{y}$, respectively. The rate of visuospatial ability did not change after stroke.

Conclusion: Among Chinese stroke survivors, incident stroke was associated with acute decline in episodic memory and visuospatial abilities, and accelerated decline in episodic memory, orientation, attention, and calculation. Cognitive training may help alleviate post-stroke cognitive impairment. 
medRxiv preprint doi: https://doi.org/10.1101/2021.09.24.21263136; this version posted September 27, 2021. The copyright holder for this preprint (which was not certified by peer review) is the author/funder, who has granted medRxiv a license to display the preprint in perpetuity.

\section{Introduction}

35 The post stroke cognitive impairment (PSCI) is topic of research interest nowadays. However, the

36 trends of cognition after stroke remains controversial. Moreover, since most studies were based on

37 stroke cohort, they were unable to learn the cognitive function before stroke. Methods such as

38 Informant Questionnaire of Cognitive Decline in the Elderly (IQCODE) could achieve information

39 on pre-stroke cognitive function. Nevertheless, they have two important limitations. First, such data

40 is self-reported and causes recall bias. Second, to avoid bias, researchers define the data as

41 dichotomous variable. This prevents us from observing the linear trends before and after stroke.

42 Several articles had reported the cognitive trend pre- and post- stroke. A 2015 JAMA article included

4323572 England participants, founding that stroke survivors experienced a faster rate of cognitive

44 decline after stroke than before stroke. A 2021 STOKE article examined ten thousand American participants, and they further reported the cognitive score of stroke survivors declined faster even before the stroke, compared with that of the stroke-free participants. To the best of knowledge, the cognitive trend among Chinese populations has not been investigated. Furthermore, there is still room for improvement of the study protocols used to calculate the trend.

Nowadays, the stroke mortality is decreasing in China, leading to increase interest in improving the life quality after stroke. Plenty of Chinese researchers make their effort to prevent dementia after stroke. Elucidating trajectories before and after stroke would be helpful in studies learning PSCI. Here, we used a national representative database, the China Health and Retirement Longitudinal Study (CHARLS), to estimate (1) the cognitive trajectories before stroke, (2) the immediate change acutely after stroke, and (3) the longitudinal cognitive change after stroke among stroke survivors.

\section{Methods}

\subsection{Study sample}

China Health and Retirement Longitudinal Study (CHARLS) is a prospective survey which designed to provide scientific research related to the aged in China. Data from wave 1 (2011-2012) to wave 4 (2018-2019) of the CHARLS were used in analyses.

In the CHARLS, a total number of 17708 participants had data on stroke and cognitive tests in 2011 (Wave 1). 349 individuals under 45 years old till 2018 were excluded. 379 individuals with a history of mental retardation or brain damage were excluded. 169 individuals with a history of memoryrelated were excluded. Among the rest 14931 participants, 7952 of them were followed up and had complete data on incident stroke and cognitive tests in the waves behind. The selection diagram and criteria for exclusion are provided in Figure 1.

\section{$66 \quad 2.2$ Cognitive assessments}

67 The cognitive dimensions of memory, visuospatial abilities, orientation, attention and calculation 68 were assessed, through three tests: episodic memory, figure drawing, and Telephone Interview of Cognitive Status (TICS). Serving as the primary outcome, the global cognition score was the sum of the three test scores. The global cognition score could range from 0 to 21 .

In the episodic memory test, the individuals were asked to recall the words immediately (immediate recall) and 5 minutes later (delayed recall) after interviewers read 10 Chinese nouns to them. The 
medRxiv preprint doi: https://doi.org/10.1101/2021.09.24.21263136; this version posted September 27, 2021. The copyright holder for this preprint (which was not certified by peer review) is the author/funder, who has granted medRxiv a license to display the preprint in perpetuity.

episodic memory score was the average score of the immediate recall and delayed recall tests and could range from 0 to 10 . This test assessed individuals' memory.

In the figure-drawing test, the individuals were shown a picture and asked to redraw it. Those who succeeded in drawing got a score of 1 . If failed, they got a score of 0 . This test examined visuospatial abilities.

The TICS test was based on selected questions from the TICS battery, a well-established measure of one's ability related to orientation, attention and calculation. In this test, the participants were asked to repeatedly subtract 7 from 100 and to identify the date, season, and day of the week. The TICS scores could range from 0 to 10 .

\subsection{Assessment of incident stroke}

We identified self-reported doctor-diagnosed incident strokes after wave 1 from stroke diagnosis newly reported at waves 2 through 4 . The date of stroke onset was recorded as being between the date of the last interview and that of the interview reporting an incident stroke.

\subsection{Covariates}

The covariates included age, gender, education, marital status, residential area, depression, current smoking, current alcohol consumption, hypertension, dyslipidaemia, diabetes or high blood sugar, instrumental activities of daily living (IADLs), cancer or malignant tumor, chronic lung diseases and heart problems.

Education level was classified as no qualification, level 1 national vocational qualification (NVQ) or certificate of secondary education, NVQ2 or General Certificate of Education (GCE) ordinary level, NVQ3 or GCE advanced level, higher qualification but below degree, and degree level or higher or NVQ4/5 (Methods available from Dryad, doi.org/10.5061/ dryad.m6v2305). IADLs could range from 0 to 5 and reflect functional status. Residential area was classified as "rural village" and "Urban Community". Depression was classified as "yes" and "no", using the 10-item Center for Epidemiologic Studies Short Depression Scale (CES-D-10). This score can range from 0 to 30, and the cut-off point for depression was 12 . Hypertension was defined as systolic blood pressure $\geq 140$ $\mathrm{mm} \mathrm{Hg}$, diastolic blood pressure $\geq 90 \mathrm{~mm} \mathrm{Hg}$, and/or self-reported treatment of hypertension with antihypertensive medication. Diabetes mellitus was defined as self-reported doctor-diagnosed diabetes mellitus, or current use of anti-diabetes therapy.

\subsection{Statistical analysis}

Linear mixed models were used to analyze longitudinal and repeated measures data. To assess the pre-stroke average difference in cognition (SD per year) between people who did and those who did not have an incident stroke, in the first model, we included group (incident stroke or not), time (years since baseline to incident stroke or the end of follow-up), time $\times$ group, age at baseline (years), gender(male or female), marital status(married or other status), education (less than NVQ3/GCE A level or NVQ3/GCE A level or greater), place(urban or rural), depressive symptoms, smoking, drinking, hypertension, dyslipidaemia, diabetes or high blood sugar, cancer or malignant tumor, chronic lung disease, heart problems, instrumental activities of daily living (IADLs). The time $\times$ group was used to assess differential change-associated incident stroke from baseline to incident stroke or the end of follow-up. To estimate the acute cognitive decline after the incident stroke, we 
medRxiv preprint doi: https://doi.org/10.1101/2021.09.24.21263136; this version posted September 27, 2021. The copyright holder for this preprint (which was not certified by peer review) is the author/funder, who has granted medRxiv a license to display the preprint in perpetuity.

113 used another model using the data of 401 participants with incident stroke. We use this model to 114 evaluate the effect of incident stroke on acute cognitive decline (the value of this variable changed

115 from 0 to 1 at the time of stroke onset).

116 SAS version 9.4 supports our analyses. All p-values were 2 tailed, and p-values $<0.05$ were 117 considered statistically significant.

\section{Results}

119 Among the 7952 participants who were included in the main analysis, 401 (5.2\%) experienced at 120 least one incident stroke during the seven-year follow-up. The baseline characteristics was shown in 121 Table 1. The mean \pm age of individuals without incidence stroke was $57.6 \pm 8.4$ years. $47.5 \%$ of 122 them were male. $67.1 \%$ of them hadn't finished high school. $81.2 \%$ lived in rural area.

123 Comparted with participants without incident stroke, those with incident stroke were older; had a 124 high number of IADLs; had lower percentages of finishing high school; had higher percentages of 125 unmarried, living in rural area, smoking, drinking, hypertension, dyslipidemia, diabetes, lung disease, 126 heart problems, and depression. There was no difference in sex proportions between the two groups.

127 The incident stroke group tended to have lower cognitive scores at baseline ( $\mathrm{P}$ value between 0.1 and 128 0.10).

\subsection{Cognitive trajectories before stroke}

130 Following our hypothesis mentioned above, the model reflected these trajectories of cognitive 131 function: (1) the predicted baseline score of the without-stroke group, (2) the decline rate of the 132 without-stroke group, (3) the difference in baseline score, (4) the difference in decline rate in the stroke group compared to the without-stroke group in the pre-stroke period, (5) the acute cognitive change after stroke among the stroke group, and (6) how much the decline rate change after stroke among the stroke group. Trajectory (1) to (5) was shown in Table 2. Trajectory (6) was shown in

136 Table 3.

As shown in Table 2 and Figure 2, there was no difference in the baseline cognitive scores between the two groups (shown by Line "Difference in intercept" in Table 2). The difference in the decline rate in the without-stroke group during seven-year follow-up, compared with the stroke group during pre-stroke period, was not statistically significant (shown by Line "Difference in slope before stroke" in Table 2). There appeared to be no difference in terms of global cognition score, episodic memory score, visuospatial ability score or executive function score.

\section{$143 \quad 3.2 \quad$ Acute cognitive decline after stroke}

144 The acute cognitive change after score was shown in Table 2 and the vertical line in Figure 2. Stroke survivors experienced an acute decline in episodic memory $(\beta,-0.123 ; 95 \% \mathrm{CI},-0.184,-0.062$;

$146 \mathrm{P}=0.043$; Model B) and visuospatial ability $(\beta,-0.187 ; 95 \% \mathrm{CI},-0.258,-0.115 ; \mathrm{P}=0.010$; Model B).

147 We did not detect significant acute cognitive decline after incident stroke in global cognition $(\beta$, $148 \quad 0.097 ; 95 \%$ CI, -0.149, -0.044; $\mathrm{P}=0.065$; Model A) and executive function $(\beta,-0.009 ; 95 \% \mathrm{CI},-0.059$, $1490.042 ; \mathrm{P}=0.862 ;$ Model A). The acute cognitive decline after stroke in episodic memory and 150 visuospatial ability was approximately equivalent to a 6-year decrease in age.

\section{$151 \quad 3.3 \quad$ Cognitive decline after stroke}


medRxiv preprint doi: https://doi.org/10.1101/2021.09.24.21263136; this version posted September 27, 2021. The copyright holder for this preprint (which was not certified by peer review) is the author/funder, who has granted medRxiv a license to display the preprint in perpetuity.

152 The long-term cognitive trajectory after stroke was shown in Table 3 and Figure 2. After stroke, the

153 global cognition score declined significantly faster than it did before stroke $(\beta,-0.074 ; 95 \% \mathrm{CI}$, -

$154 \quad 0.093,-0.054 ; \mathrm{P}<0.001)$. The decline rate of the post-stroke period was about one times faster than

155 that of the pre-stroke period. We observed decrease in the slopes of episodic memory $(\beta,-0.043 ; 95 \%$

$156 \mathrm{CI},-0.063,-0.049 ; \mathrm{P}=0.034)$ and executive function $(\beta,-061 ; 95 \% \mathrm{CI},-0.078,-0.045 ; \mathrm{P}<0.001)$ after

157 incident stroke compared with pre-stroke slopes. The decline rate of visuospatial ability did not

158 change after incident stroke.

\section{$159 \quad 3.4 \quad$ Sensitivity analysis}

160 We conducted sensitivity analysis in several parts: retained participants with missing cognitive data, 161 retained participants with missing cognitive data and baseline stroke history, retained participants 162 with baseline stroke history, exclude participants experienced one more stroke during the follow-up.

\section{Discussion}

164 Through the analysis of CHARLS, we observed that compared with individuals who did not have a stroke, individuals who had a stroke showed an accelerated cognitive decline before the stroke. In addition, compared with the slope of the cognitive decline curve before stroke, the curve of cognitive decline in stroke patients is steeper.

168 Compared with existing longitudinal studies, one study compared the rate of cognitive decline in 169 stroke patients before the onset of stroke with the rate of cognitive decline in individuals without stroke. Researchers report that stroke patients have a faster memory loss before the onset of stroke than people who have not had a stroke. This is consistent with our findings that in all tested areas, the decline before stroke is accelerated. However, it did not investigate the difference between the slope of the cognitive decline curve for stroke patients and the slope of the non-stroke sample cognitive decline, but used the combined pre-stroke slope as the baseline slope.

Another important conclusion is that, in the long term, stroke patients have a faster sustained cognitive decline after a stroke event. This is consistent with previous studies that reported that cognitive function declines faster in the long term, although several other studies have shown that cognitive decline does not accelerate after a stroke. These conflicting results may be due to follow-up deviation, the choice of covariates, the deviation of cognitive assessment, and the length of follow-up time. Our results are based on long-term follow-up data from a large number of general populations, and multiple evaluations of cognitive performance before stroke in multiple dimensions.

182 One of the main advantages of our study is that this is a large and national-representative sample of 183 middle-aged and older Chinese, which help us study the progression of cognitive decline before and after stroke. Another advantage is that cognitive function is repeatedly measured during the followup period, which allows us to accurately plot the decline of cognitive function and quantify the course of cognitive decline. Our research design also allows us to capture the cognitive performance of participants before the stroke and better predict the acute cognitive decline after the stroke and the continuous cognitive decline thereafter.

189 However, this study also has certain limitations. In this study, the most important issue is the definition of stroke. We use self-reported doctor-diagnosed stroke events as the inclusion criteria. This may lead to misclassification of stroke cases and bias ours to a certain extent. Research result. Second, we cannot obtain accurate information on the date of onset of stroke, location, stroke classification, stroke severity, and treatment in the acute phase; therefore, we cannot control these 
medRxiv preprint doi: https://doi.org/10.1101/2021.09.24.21263136; this version posted September 27, 2021. The copyright holder for this preprint (which was not certified by peer review) is the author/funder, who has granted medRxiv a license to display the preprint in perpetuity.

194 factors in our study. Third, although we adjusted some potential confounding factors, we cannot rule

195 out the possibility of residual confounding, including genetic predisposition factors, such as APOE

196 genotype. At present, the regulatory effect of apolipoprotein E genotype on the association between

197 stroke and cognitive outcome is still unclear, and some studies have shown that there is a synergistic

198 effect between stroke and cognitive outcome. In addition, some samples were excluded from our

199 analysis. Therefore, there is a possibility of selection bias. Finally, this study uses isolation tests to

200 measure cognitive function. It is important to choose different cognitive function measurement

201 methods. More detailed and comprehensive neuropsychological assessments may reveal stronger

202 connections.

203 Our results clearly show that during the follow-up period, cognitive decline before stroke and

204 cognitive decline after stroke are associated with stroke events.

2055 Tables

206

207

\subsection{Table 1. Baseline characteristics of participants with or without incident stroke during follow-up}

\begin{tabular}{|c|c|c|c|}
\hline & $\begin{array}{c}\text { No incident stroke } \\
(\mathrm{n}=7551)\end{array}$ & $\begin{array}{c}\text { Incident stroke } \\
(\mathrm{n}=401)\end{array}$ & $\mathrm{P}$ \\
\hline \multicolumn{4}{|l|}{ Continuous variables } \\
\hline Age & $57.6(8.4)$ & $60.3(8.4)$ & $<0.001$ \\
\hline $\begin{array}{l}\text { Number of IADLs } \\
\text { Global cognition } \\
\text { Episodic memory } \\
\text { Visuospatial ability } \\
\text { Executive function }\end{array}$ & $\begin{array}{l}0.1(0.5) \\
11.0(4.0) \\
3.5(1.9) \\
0.7(0.5) \\
6.9(2.7)\end{array}$ & $\begin{array}{l}0.2(0.6) \\
10.5(3.9) \\
3.3(1.8) \\
0.7(0.5) \\
6.6(2.8)\end{array}$ & $\begin{array}{l}0.016 \\
0.015 \\
0.053 \\
0.063 \\
0.041\end{array}$ \\
\hline \multicolumn{4}{|l|}{ Categorical variables, n (\%) } \\
\hline Males & $3586(47.5)$ & $188(46.9)$ & 0.635 \\
\hline Education & & & $<0.001$ \\
\hline Illiterate & $1633(21.3)$ & $98(24.4)$ & \\
\hline Primary school & $3259(41.8)$ & $181(45.1)$ & \\
\hline Middle school & $1804(23.9)$ & $70(17.5)$ & \\
\hline High school and above & $955(12.7)$ & $52(13.0)$ & \\
\hline Marital status & & & $<0.001$ \\
\hline Married & $6891(91.3)$ & $349(87.0)$ & \\
\hline Other status & $660(8.7)$ & $52(13.0)$ & \\
\hline Residential area & & & 0.248 \\
\hline Urban & $1419(18.8)$ & $80(20.0)$ & \\
\hline Rural & $6132(81.2)$ & $321(80.1)$ & \\
\hline Current smoking & $2893(38.3)$ & $169(42.1)$ & 0.002 \\
\hline Current drinking & $1935(25.6)$ & $116(28.9)$ & 0.003 \\
\hline Hypertension & $1579(20.9)$ & $172(42.9)$ & $<0.001$ \\
\hline Dyslipidemia & $640(8.5)$ & $72(18.0)$ & $<0.001$ \\
\hline Diabetes & $387(5.1)$ & $41(10.2)$ & $<0.001$ \\
\hline
\end{tabular}

This is a provisional file, not the final typeset article 
medRxiv preprint doi: https://doi.org/10.1101/2021.09.24.21263136; this version posted September 27, 2021. The copyright holder for this preprint (which was not certified by peer review) is the author/funder, who has granted medRxiv a license to display the preprint in perpetuity.

All rights reserved. No reuse allowed without permission.

Running Title

Cancer

Lung Diseases

Heart problems

Depression
$63(0.8)$

687 (9.1)

808 (10.7)

1468 (19.4)
$3(0.8)$

43 (10.7)

76 (18.95)

$100(25.0)$
0.711

0.028

$<0.001$

0.007 


\begin{tabular}{|c|c|c|c|c|c|c|c|c|c|c|c|c|c|c|c|c|}
\hline & \multicolumn{4}{|c|}{ Global cognition } & \multicolumn{4}{|c|}{ Episodic memory } & \multicolumn{4}{|c|}{ Visuospatial ability } & \multicolumn{4}{|c|}{ Executive function } \\
\hline & \multicolumn{2}{|l|}{ Model A } & \multicolumn{2}{|l|}{ Model B } & \multicolumn{2}{|l|}{ Model A } & \multicolumn{2}{|l|}{ Model B } & \multicolumn{2}{|l|}{ Model A } & \multicolumn{2}{|l|}{ Model B } & \multicolumn{2}{|l|}{ Model A } & \multicolumn{2}{|l|}{ Model B } \\
\hline & $\begin{array}{l}\beta \\
(95 \% \mathrm{CI})\end{array}$ & $P$ & $\begin{array}{l}\beta \\
(95 \% \mathrm{CI})\end{array}$ & $\mathrm{P}$ & $\begin{array}{l}\beta \\
(95 \% \mathrm{CI})\end{array}$ & $P$ & $\begin{array}{l}\beta \\
(95 \% \mathrm{CI})\end{array}$ & $\mathrm{P}$ & $\begin{array}{l}\beta \\
(95 \% \mathrm{CI})\end{array}$ & $P$ & $\begin{array}{l}\beta \\
(95 \% \mathrm{CI})\end{array}$ & $\mathrm{P}$ & $\begin{array}{l}\beta \\
(95 \% \mathrm{CI})\end{array}$ & $\mathrm{P}$ & $\begin{array}{l}\beta \\
(95 \% \mathrm{CI})\end{array}$ & $P$ \\
\hline Variables & & & & & & & & & & & & & & & & \\
\hline Baseline age & $\begin{array}{l}-0.014 \\
(-0.014,- \\
0.013)^{*}\end{array}$ & $<0.001$ & $\begin{array}{l}-0.014 \\
(-0.014,- \\
0.013)\end{array}$ & $<.001$ & $\begin{array}{l}-0.020 \\
(-0.021,- \\
0.020)\end{array}$ & $<0.001$ & $\begin{array}{l}-0.020 \\
(-0.021,- \\
0.020)\end{array}$ & $<.001$ & $\begin{array}{l}-0.010 \\
(-0.011,- \\
0.009)\end{array}$ & $<0.001$ & $\begin{array}{l}-0.010 \\
(-0.011,- \\
0.009)\end{array}$ & $<0.001$ & $\begin{array}{l}-0.005 \\
(-0.006,- \\
0.004)\end{array}$ & $<0.001$ & $\begin{array}{l}-0.005 \\
(-0.006,- \\
0.004)\end{array}$ & $<0.001$ \\
\hline $\begin{array}{l}\text { Intercept of } \\
\text { without-stroke } \\
\text { group }\end{array}$ & $\begin{array}{l}0.080 \\
(0.008, \\
0.153)\end{array}$ & 0.270 & $\begin{array}{l}0.080 \\
(0.008, \\
0.153)\end{array}$ & 0.270 & $\begin{array}{l}0.507 \\
(0.439, \\
0.575)\end{array}$ & $<0.001$ & $\begin{array}{l}0.508 \\
(0.441, \\
0.576)\end{array}$ & $<.001$ & $\begin{array}{l}0.243 \\
(0.175, \\
0.31)\end{array}$ & $<0.001$ & $\begin{array}{l}0.242 \\
(0.174, \\
0.309)\end{array}$ & $<0.001$ & $\begin{array}{l}0.071 \\
(0.005, \\
0.136)\end{array}$ & 0.279 & $\begin{array}{l}0.071 \\
(0.005, \\
0.136)\end{array}$ & 0.279 \\
\hline $\begin{array}{l}\text { Difference in } \\
\text { intercept }^{b}\end{array}$ & $\begin{array}{l}0.030 \\
(-0.010, \\
0.069)\end{array}$ & 0.454 & $\begin{array}{l}-0.024 \\
(-0.066, \\
0.018)\end{array}$ & 0.566 & $\begin{array}{l}0.048 \\
(0.005, \\
0.091)\end{array}$ & 0.268 & $\begin{array}{l}0.018 \\
(-0.027 \\
0.063)\end{array}$ & 0.685 & $\begin{array}{l}-0.013 \\
(-0.059 \\
0.033)\end{array}$ & 0.776 & $\begin{array}{l}0.005 \\
(-0.043 \\
0.053)\end{array}$ & 0.919 & $\begin{array}{l}0.014 \\
(-0.023 \\
0.051)\end{array}$ & 0.702 & $\begin{array}{l}-0.03 \\
(-0.069 \\
0.009)\end{array}$ & 0.444 \\
\hline $\begin{array}{l}\text { Slope of } \\
\text { without-stroke } \\
\text { group }\end{array}$ & $\begin{array}{l}-0.045 \\
(-0.047,- \\
0.044)\end{array}$ & $<0.001$ & $\begin{array}{l}-0.045 \\
(-0.047,- \\
0.044)\end{array}$ & $<0.001$ & $\begin{array}{l}-0.010 \\
(-0.012,- \\
0.008)\end{array}$ & $<0.001$ & $\begin{array}{l}-0.010 \\
(-0.012,- \\
0.008)\end{array}$ & $<0.001$ & $\begin{array}{l}-0.052 \\
(-0.054,- \\
0.051)\end{array}$ & $<0.001$ & $\begin{array}{l}-0.052 \\
(-0.054,- \\
0.051)\end{array}$ & $<0.001$ & $\begin{array}{l}-0.046 \\
(-0.047,- \\
0.045)\end{array}$ & $<0.001$ & $\begin{array}{l}-0.046 \\
(-0.047,- \\
0.045)\end{array}$ & $<0.001$ \\
\hline $\begin{array}{l}\text { Difference in } \\
\text { slope before } \\
\text { stroke }^{c}\end{array}$ & $\begin{array}{l}-0.021 \\
(-0.031,- \\
0.011)\end{array}$ & 0.035 & $\begin{array}{l}0.004 \\
(-0.008, \\
0.016)\end{array}$ & 0.718 & $\begin{array}{l}-0.014 \\
(-0.025,- \\
0.003)\end{array}$ & 0.224 & $\begin{array}{l}0.000 \\
(-0.013 \\
0.013)\end{array}$ & 0.976 & $\begin{array}{l}0.003 \\
(-0.010, \\
0.016)\end{array}$ & 0.841 & $\begin{array}{l}-0.005 \\
(-0.02, \\
0.009)\end{array}$ & 0.713 & $\begin{array}{l}-0.019 \\
(-0.029,- \\
0.01)\end{array}$ & 0.043 & $\begin{array}{l}0.002 \\
(-0.009 \\
0.013)\end{array}$ & 0.878 \\
\hline $\begin{array}{l}\text { Acute change } \\
\text { after stroke }^{d}\end{array}$ & $\begin{array}{l}-0.097 \\
(-0.149,- \\
0.044)\end{array}$ & 0.065 & $\begin{array}{l}-0.056 \\
(-0.109,- \\
0.002)\end{array}$ & 0.298 & $\begin{array}{l}-0.16 \\
(-0.218,- \\
0.101)\end{array}$ & 0.006 & $\begin{array}{l}-0.123 \\
(-0.184,- \\
0.062)\end{array}$ & 0.043 & $\begin{array}{l}-0.159 \\
(-0.228,- \\
0.09)\end{array}$ & 0.021 & $\begin{array}{l}-0.187 \\
(-0.258,- \\
0.115)\end{array}$ & 0.010 & $\begin{array}{l}-0.009 \\
(-0.059 \\
0.042)\end{array}$ & 0.862 & $\begin{array}{l}0.032 \\
(-0.019 \\
0.084)\end{array}$ & 0.533 \\
\hline Log likelihood & -34316.0 & & -34303.3 & & -37044.1 & & -37039.0 & & -40773.5 & & -40772.3 & & -32127.0 & & -32117.6 & \\
\hline
\end{tabular}

*All coefficients and confidence intervals were shown in the form of $\mathrm{z}$ score.

aAdjusted for baseline age (shown in Line "Baseline age"), sex, education, marital status, residential area, current smoking, current drinking, hypertension, dyslipidemia, diabetes, cancer, lung diseases, heart problems, depression, and number of IADLs. depression, and number of IADLs.

${ }^{\mathrm{b}}$ The difference in intercept in the stroke group compared to the without-stroke group.

${ }^{\mathrm{c}}$ The difference in slope rate in the stroke group during pre-stroke period compared to the without-stroke group during the whole follow-up period. 
medRxiv preprint doi: https://doi.org/10.1101/2021.09.24.21263136; this version posted September 27, 2021. The copyright holder for this preprint (which was not certified by peer review) is the author/funder, who has granted medRxiv a license to display the preprint in perpetuity.

All rights reserved. No reuse allowed without permission.

\subsection{Table 3. Changes in slope after incident stroke compared with slope before incident stroke $^{\mathrm{a}, \mathrm{b}}$}

\begin{tabular}{lll}
\hline & $\beta(95 \% \mathrm{CI})$ & P value \\
\hline Global cognition & $-0.074(-0.093,-0.054)^{*}$ & $<0.001$ \\
Episodic memory & $-0.043(-0.063,-0.023)$ & 0.034 \\
Visuospatial ability & $0.027(0.005,0.049)$ & 0.215 \\
Executive function & $-0.061(-0.078,-0.045)$ & $<0.001$
\end{tabular}

*All coefficients and confidence intervals were shown in the form of $\mathrm{z}$ score.

${ }^{a}$ Adjusted for age, sex, education, marital status, residential area, current smoking, current drinking, hypertension, dyslipidemia, diabetes, cancer, lung diseases, heart problems, depression, and number of IADLs.

$225{ }^{\mathrm{b}}$ The coefficient reflected the amount of the slope changed after incident stroke among the stroke 226 group. 
medRxiv preprint doi: https://doi.org/10.1101/2021.09.24.21263136; this version posted September 27, 2021. The copyright holder for this preprint (which was not certified by peer review) is the author/funder, who has granted medRxiv a license to display the preprint in perpetuity. All rights reserved. No reuse allowed without permission.

\section{Figure legends}

\section{Figure 1. Flow chart of participant selection.}

235 Figure 2. Predicted changes in cognitive $z$ scores among all participants during the follow-up. 236 The 70-year old woman is fictitious and not based on a real individual from our source

237 datasets. The black lines represented participants without incident stroke. The blue lines represented 238 the pre-stroke cognitive trajectory among participants with incident stroke. The red lines reflected the 239 cognitive trajectory after incident stroke. The predicted values of cognitive score were calculated for 240 a 70-year-old female. She hadn't finished primary school, lived in rural area, and had an IADL score 241 of two. She was married, current smoking, not current drinking, hypertension. She did not have 242 dislipidiemia, diabetes, cancer, lung diseases, heart problems, or depression. She experienced one incident stroke at the end of the third year. 
medRxiv preprint doi: https://doi.org/10.1101/2021.09.24.21263136; this version posted September 27, 2021. The copyright holder for this preprint (which was not certified by peer review) is the author/funder, who has granted medRxiv a license to display the preprint in perpetuity. All rights reserved. No reuse allowed without permission.

\section{Conflict of Interest}

246 All financial, commercial or other relationships that might be perceived by the academic community as representing a potential conflict of interest must be disclosed. If no such relationship exists, authors will be asked to confirm the following statement:

249 The authors declare that the research was conducted in the absence of any commercial or financial

250 relationships that could be construed as a potential conflict of interest.

\section{Author Contributions}

252 The Author Contributions section is mandatory for all articles, including articles by sole authors. If an appropriate statement is not provided on submission, a standard one will be inserted during the production process. The Author Contributions statement must describe the contributions of individual authors referred to by their initials and, in doing so, all authors agree to be accountable for the content of the work. Please see here for full authorship criteria.

\section{Funding}

258 Details of all funding sources should be provided, including grant numbers if applicable. Please

259 ensure to add all necessary funding information, as after publication this is no longer possible.

\section{$260 \quad 10 \quad$ Acknowledgments}

261 This is a short text to acknowledge the contributions of specific colleagues, institutions, or agencies

262 that aided the efforts of the authors.

\section{References}

264 The following formatting styles are meant as a guide, as long as the full citation is complete and

265 clear, Frontiers referencing style will be applied during typesetting. 
17708 individuals were interviewed in the first wave

(Wave 1) of CHARLS during 2011-2012

15828 individuals completed cognitive tests in Wave 1

897 Excluded

- 349 Less than 45 years age at baseline

- 379 Brain damage/mental retardation

- 169 Memory-related disease

14931 individuals in Wave 1

6979 Excluded

- 389 History of stroke

- $\mathbf{6 5 7 4}$ No cognitive tests in Wave 2 to Wave 4

- 16 No baseline covariates

7952 individuals included in main analysis

7551 with no incident stroke

- $\mathbf{4 0 1}$ with incident stroke 
A

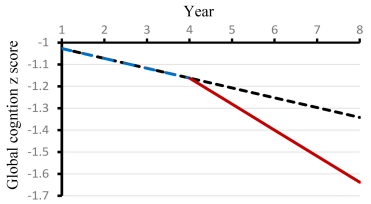

C

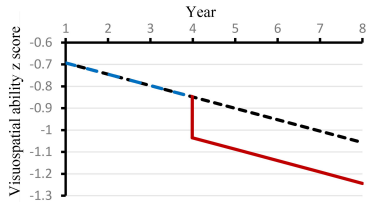

B

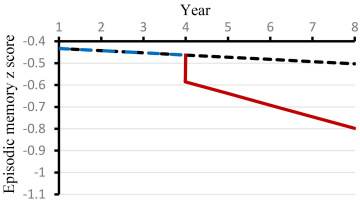

D

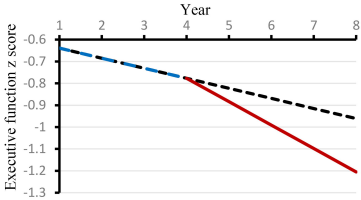

